\title{
Five interval colorectal cancers
}

A 78-year-old man presented with anemia and melena in 2010. His past history included resection of a sigmoid carcinoma in 1997. Colonoscopies in 1999 and 2000 had shown polyps. A repeat colonoscopy for anemia in 2001 had shown two interval cancers in the ascending and transverse colon, and a right hemicolectomy had been performed. Surveillance colonoscopies in 2002, 2003, and 2005 showed only hyperplastic polyps in 2003.

Colonoscopy in 2010 revealed hyperplastic and adenomatous polyps of various sizes and three cancers in the remaining colon ( Fig. 1).

The polyps were easily visualized; the cancers were all discovered in fixed folds from prior surgery making visualization very difficult. The histology of each cancer was different. Immunohistochemistry showed loss of MLH1 and PMS2 for all cancers, which confirmed that the patient had Lynch syndrome [2].

This patient developed six individual colon cancers over a 13-year period; five of the six cancers developed during surveillance. We propose two possible explanations for this: (i) the cancers grew unusually fast, or (ii) cancers or precursor lesions were missed during preceding colonoscopies $[3,4]$. As the two cancers in 2001 were discovered after an interval of only 11 months since the previous colonoscopy, we believe that they were missed. It is likely that lesions were missed in 2005 as well, as all three cancers discovered in 2010 were located inside of or proximal to fixed folds related to previous surgeries, which made discovery difficult. In addition, it is highly improbable that this patient with two mutations associated with Lynch syndrome did not develop any polyps for 5 years, and then presented with the entire range of lesions in 2010, as he had done previously in 2001.

What can we learn from this case? First, Lynch syndrome should have been diagnosed in 2001. Second, the colonoscopy interval for this patient should have been 1-2 years, especially given the occurrence of two interval cancers in 2001 within 11 months of the previous colonoscopy. Finally, complete inspection with removal of all mucosa or polyps that appear abnormal is critical in the prevention of additional colorectal cancer in patients with a history of colorectal cancer and in particular with Lynch syndrome.

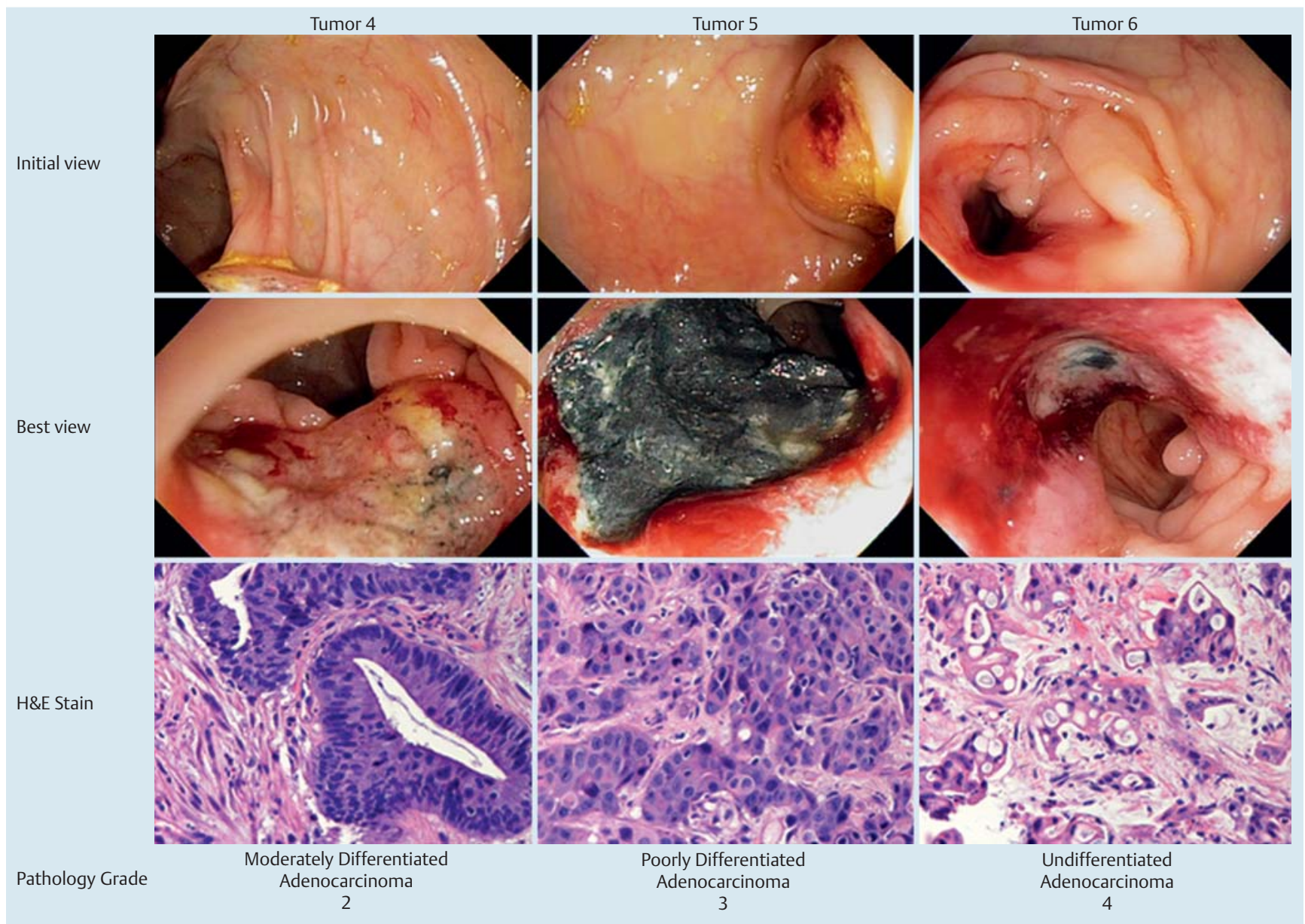

Fig. 1 Three cancers of the colon discovered in 2010. Top row: The initial endoscopic view of each cancer. Middle row: The best endoscopic view of each cancer. Bottom row: Histological appearance of each cancer (hematoxylin and eosin [H\&E]). Pathological diagnosis and tumor grade [1] are shown below the images for each cancer. 


\section{Endoscopy_UCTN_Code_CCL_1AD_2AC}

\section{Competing interests: None}

J. Edakkanambeth Varayil ${ }^{1}$, T. C. Smyrk ${ }^{2}$, P. C. de Groen ${ }^{1}$

1 Division of Gastroenterology and Hepatology, Mayo Clinic, Rochester, Minnesota, USA

2 Department of Laboratory Medicine and Pathology, Mayo Clinic, Rochester Minnesota, USA

\section{References}

1 Greene FL, Page DL, Fleming ID et al. eds. AJCC Cancer Staging Manual. 6th edn. Philadelphia: Lippincott-Raven; 2002: 113-124

2 de Jong AE, Hendriks YMC, Kleibeuker JH et al. Decrease in mortality in Lynch syndrome families because of surveillance. Gastroenterology 2006; 130: 665-671

3 Brenner H, Haug H, Arndt V et al. Low risk of colorectal cancer and advanced adenomas more than 10 years after negative colonoscopy. Gastroenterology 2010; 138: 874876

4 Singh H, Nugent Z, Mahmud MS et al. Predictors of colorectal cancer after negative colonoscopy: a population-based study. Am J Gastroenterol 2010; 105: 669-673

\section{Bibliography}

DOI $10.1055 / \mathrm{s}-0030-1256378$

Endoscopy 2011; 43: E203 -E204

(c) Georg Thieme Verlag KG Stuttgart · New York . ISSN 0013-726X

\section{Corresponding author}

\section{P. C. de Groen, MD}

Department of Medicine,

Division of Gastroenterology and Hepatology, Mayo Clinic

200 First Street S.W.

Rochester, MN 55905

USA

Fax: +1-507-284-0538 